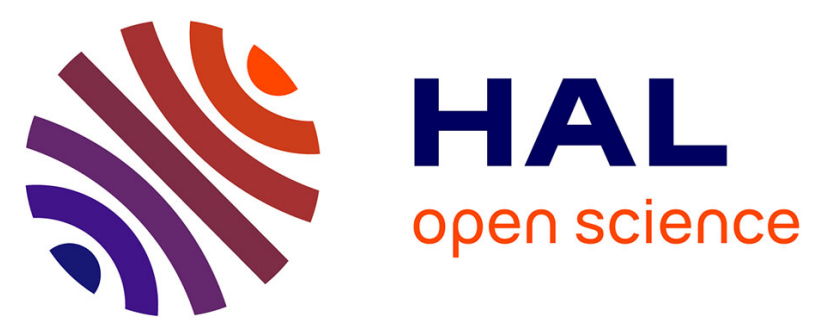

\title{
Azacalixphyrins as an Innovative Alternative for the Free-Radical Photopolymerization under Visible and NIR Irradiation without the Need of Co-Initiators
}

\author{
Louise Breloy, Rana Mhanna, Jean-Pierre Malval, V. Brezova, Denis
} Jacquemin, Simon Pascal, Olivier Siri, Davy-Louis Versace

\section{To cite this version:}

Louise Breloy, Rana Mhanna, Jean-Pierre Malval, V. Brezova, Denis Jacquemin, et al.. Azacalixphyrins as an Innovative Alternative for the Free-Radical Photopolymerization under Visible and NIR Irradiation without the Need of Co-Initiators. Chemical Communications, 2021, 57 (71), pp.8973-8976. 10.1039/D1CC03607F . hal-03318918

\section{HAL Id: hal-03318918 https://hal.science/hal-03318918}

Submitted on 6 Sep 2021

HAL is a multi-disciplinary open access archive for the deposit and dissemination of scientific research documents, whether they are published or not. The documents may come from teaching and research institutions in France or abroad, or from public or private research centers.
L'archive ouverte pluridisciplinaire HAL, est destinée au dépôt et à la diffusion de documents scientifiques de niveau recherche, publiés ou non, émanant des établissements d'enseignement et de recherche français ou étrangers, des laboratoires publics ou privés. 


\title{
Azacalixphyrins as an Innovative Alternative for the Free-Radical Photopolymerization under Visible and NIR Irradiation without the Need of Co-Initiators
}

\author{
Louise Breloy, ${ }^{a}$ Rana Mhanna, ${ }^{b}$ Jean-Pierre Malval, ${ }^{b}$ Vlasta Brezová, ${ }^{c}$ Denis Jacquemin, ${ }^{* d}$ Simon \\ Pascal, ${ }^{e}$ Olivier Siri, ${ }^{*}$ and Davy-Louis Versace ${ }^{* a}$
}

\begin{abstract}
Azacalixphyrins are unique aromatic macrocycles featuring strong absorption from the visible to the near-infrared (NIR) spectral ranges. This work demonstrates through EPR spin-trapping experiments that the $\mathrm{N}$-alkyl tetrasubstituted azacalixphyrin (ACP) can lead to the formation of carbon-centered radicals initiating for the free-radical photopolymerization (FRP) of bio-based acrylate monomer upon the irradiation of several light emitting diodes, which emissions range from 455 to $660 \mathrm{~nm}$. Compared to other previously reported systems, the tremendous advantage of the ACP photoinitiating system is its ability to promote photopolymerization on its own, avoiding the introduction of co-initiators. A new potential application of this promising photoinitiator is highlighted through the fabrication of well-defined microstructures under NIR laser diode irradiation at $\lambda$ $=800 \mathrm{~nm}$.

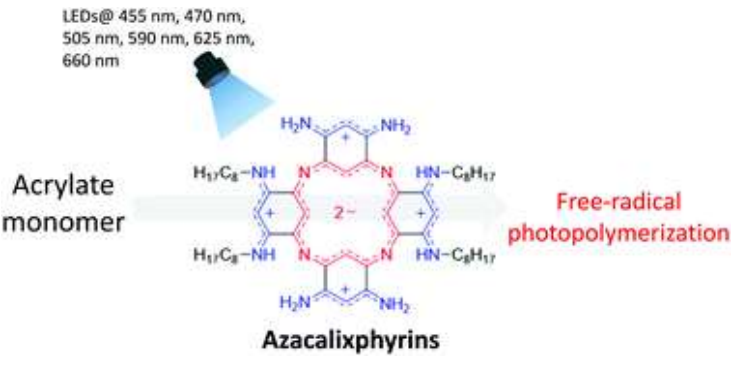

\section{Introduction}

Photopolymerization has attracted much attention these last decades with numerous applications in electronics, coatings, ${ }^{1-2}$ medicine ${ }^{3-4}$ and more recently in 3D-printing ${ }^{5-6}$. Since the photopolymerization process is originally activated by UV-light, handling issues and high energetic consumption of UV-light sources prompted researchers to find new photoinitiating systems performing under visible-light and near-infrared (NIR) irradiation. ${ }^{7}$ Increasing excitation wavelength allows application of safe and low-energy light sources such as visible LEDs, and lead the light to a penetrate deeper in the matter. ${ }^{8}$ When UVinduced polymerization applications were often limited to thin coatings $(<50 \mu \mathrm{m})$, NIR-photoinitiating systems could lead the polymerization of thick samples up to a few centimetres, ${ }^{9-10}$ but also polymerization through thick barriers such as animal skins. ${ }^{11}$ Many performing visible-light photoinitiating systems

a. Institut de Chimie et des Matériaux Paris-Est (UMR-CNRS 7182-UPEC), 2-8 rue Henri Dunant, 94320 Thiais. Corresponding author: versace@icmpe.cnrs.fr

b. Institut de Science des Matériaux de Mulhouse (IS2M) (UMR-CNRS 7361), 15, rue Jean Starcky, 68057 Mulhouse

Slovak University of Technology in Bratislava, Faculty of Chemical and Food Technology, Institute of Physical Chemistry and Chemical Physics, Department of Physical Chemistry, Radlinského 9, SK-812 37 Bratislava, Slovak Republic.

d. Université de Nantes, CEISAM UMR 6230, CNRS, F-44000 Nantes, France. Denis.Jacquemin@univ-nantes.fr

e. Aix Marseille Univ, CNRS UMR 7325, Centre Interdisciplinaire de Nanoscience de Marseille (CINaM), Campus de Luminy, case 913, 13288 Marseille cedex 09, France.olivier.siri@univ-amu.fr

Electronic Supplementary Information (ESI) available: Exp. section, ${ }^{1} \mathrm{H}$ NMR spectrum of ACP; chemical structure of SOA; absorbance spectrum of ACP in SOA kinetic profiles for the free-radical polymerization; initiation mechanism of SOA by acrylate monomer; additional DFT and TD-DFT data. See DOI: 10.1039/x0xx00000x were developed, based on dye photosensitizers ${ }^{12-14}$ or common UV photoinitiators with the red-shifted absorption. ${ }^{15-16}$ However, promoting free-radical photopolymerization (FRP) under far-red and NIR irradiation remains a huge challenge, as the associated photons carry less energy. Nevertheless, few systems dedicated to NIR-photopolymerization have emerged recently. ${ }^{17-20}$ Among the most promising far-red and NIR photosensitizers (PS), highly conjugated macrocycles such as porphyrins and phthalocyanines stand out and were extensively explored because of their high molar extinction coefficients up to the NIR $21-22\left(>1000 \mathrm{M}^{-1} \mathrm{~cm}^{-1}\right)$. Some works, notably by Boyer's team, report the initiation of photoinduced electron/energy transfer-reversible addition-fragmentation chain transfer (PETRAFT) using porphyrins as reductant of RAFT agent. ${ }^{23-31}$ Phthalocyanines were also used for PET-RAFT, but required the exploration of unusual reaction pathways, i.e. radical formed on the solvent ${ }^{32}$ or photosensitization of endoperoxides. ${ }^{11}$ Concerning FRP, classical photoinitiating systems based on macrocycles, using iodonium salt or amines as co-initiators, are well-adapted to visible-light photopolymerization. ${ }^{21-22,33-35}$ However, they often fail to initiate polymerization at higher wavelength $(\lambda>550 \mathrm{~nm})$, despite their strong radiation absorption. ${ }^{22,} 33$ As a consequence, Lalevée and co-workers suggested to use a combination of three- or four-components photoinitiating systems containing PS, for instance phthalocyanines $^{9}$ or porphyrins, ${ }^{36-37}$ iodonium salt, phosphine derivative as oxygen inhibitor, and eventually a photothermal initiator. Rodgers et al. ${ }^{38}$ initiated FRP under red light thanks to 
a derivative of Vitamin B12, leading to the cleavage of Co-C bond at high wavelength generating alkyl radicals. These uncommon systems underline the difficulty of finding efficient photoinitiating systems in the far-red and NIR ranges. In this context, the azacalixphyrin macrocycle may be interesting alternatives due to their NIR absorption but they were never investigated as photoinitiator. The first preparation of the unsubstituted azacalixphyrin macrocycle was reported in 2013 highlighting the access to an unique panchromatic and NIRabsorbing bis-zwitterion in no more than two synthetic steps. ${ }^{39}$ More recently, the decoration of the periphery of that macrocycle with $\mathrm{N}$-substituents (e.g. ACP, see Chart 1) allowed improving the solubility in organic solvents, tuning the optical properties, and revealed that the protonation of the ACP is prompt and occurs in protic medium, thereby enhancing the intensity of the lower energy absorption band. ${ }^{40-42}$ The strong NIR absorption of azacalixphyrins ca. $900 \mathrm{~nm}$ was useful to develop photoacoustic contrast agents and this maximum absorption has been recently shifted to the short wavelength infrared range, beyond $1000 \mathrm{~nm}$, through the development of a highly delocalized fused bis-azacalixphyrin. ${ }^{43}$

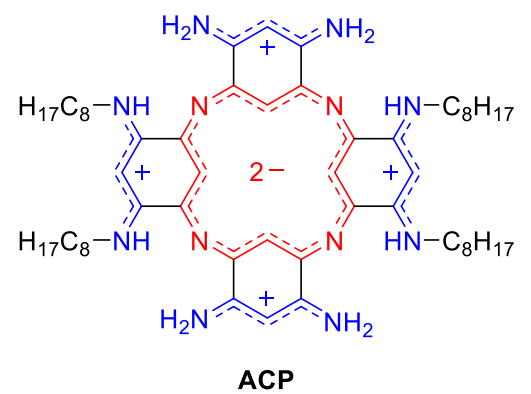

Chart 1. Structure of the N-octyl ACP.

This work reports the first use of the $N$-alkyl tetrasubstituted ACP as an innovative visible and NIR absorbing photoinitiator without the need of any co-initiator. Free-radical photopolymerization of a bio-based monomer, soybean oil acrylate (SOA), in the presence of ACP was demonstrated under LED@455, 470, 505, 590, 625 and 660 nm exposure, and under NIR irradiation at $800 \mathrm{~nm}$. The initiation mechanism was supported by electron paramagnetic resonance (EPR) spin trapping experiments and theoretical studies, and the kinetic profiles were followed by Real-Time Fourier Transform InfraRed (RT-FTIR) spectroscopy. Interestingly a well-defined twodimensional micro-structure was synthesized by stereolithography with a laser source at $800 \mathrm{~nm}$.

\section{Results and discussion}

Absorption properties. The strong and panchromatic absorbance of azacalixphyrins goes up to $c a .1000 \mathrm{~nm},,^{40-41}$ and the absorption spectrum of ACP conveniently matches with the emission spectra of several LEDs used in this study (LEDs@455, 470, 505, 590, 625 and $660 \mathrm{~nm}$, see Figure 1). We highlight that ACP shows very high molar extinction coefficients at the aforementioned wavelengths in methanol (Figure 1, Table S1) or in the acrylate monomer (Figure S1).
Also, a quite intense absorption is observed at $800 \mathrm{~nm}$, wavelength commonly met in NIR laser diode. This makes ACP a promising candidate as photoinitiator for visible-light and NIR FRP. The nature of the absorption band of ACP has been investigated before, ${ }^{36,37}$ and additional TD-DFT can be found in the ESI (Table S2 and Figure S2).

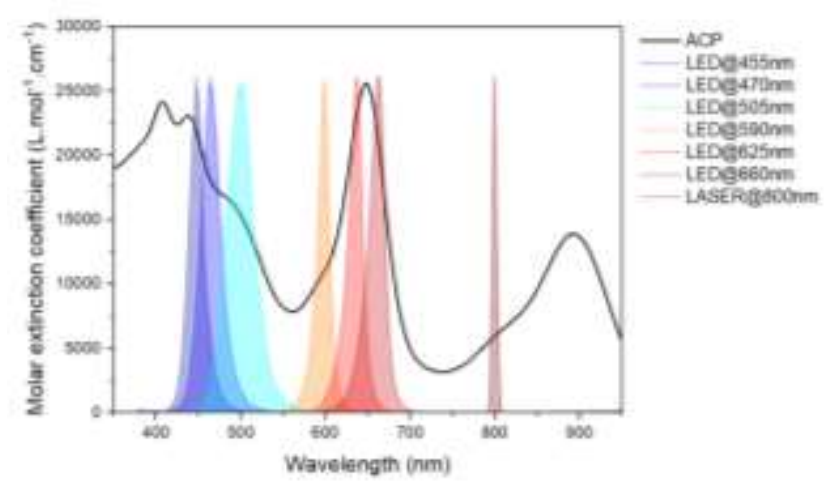

Figure 1. Absorption spectra of ACP in methanol superimposed with emission spectra of several LEDs.

Generation of radicals under light activation. To initiate FRP, an absorbing molecule must be able to generate reactive species. As stated in the introduction, highly absorbing macrocycles (porphyrins or phthalocyanines) have attracted much attention these last years as photosensitizers to initiate FRP in the visible ${ }^{15,21-22,34-35}$ and/or NIR range. ${ }^{9}, 36-37$ However, co-initiators are typically required for generating radicals. In a previous work 22 we demonstrated that a metal-free dimethylaminophenyl-substituted phthalocyanine is able to generate under light irradiation, carbon-centred radicals on its own, allowing FRP of trimethylolpropane triacrylate (TMPTA). The initiating radicals were formed by intramolecular electron transfer between the macrocycle and the dimethylamino groups, replacing amine co-initiator. Interestingly, ACP includes octylamino groups on its structure, which prompted us to investigate the formation of radicals using EPR spin trapping technique.

The photoactivation of an ACP/DMSO/DMPO/argon solution using LED@450 nm or LED@VIS sources led to the generation of lowintensity noisy six-line signal with the spin-Hamiltonian parameters $a_{\mathrm{N}}=1.489 \mathrm{mT}, a_{\mathrm{H}}{ }^{\beta}=2.063 \mathrm{mT} ; g=2.0058$ corresponding to the DMPO-adduct with a carbon-centred radical. The EPR signal intensity of this DMPO-adduct remained very low, despite the prolonged LED exposure (Figure S3) was applied, and we cannot exclude that this signal originated from solvent. Consequently, further EPR experiments were performed using POBN, i.e., a reactive nitrone spin trap soluble in DMSO solvent possessing a sufficient light-stability under given experimental conditions, as evidenced by the blank experiments. The LED@VIS exposure ( $450 \mathrm{~nm}$ ) of ACP/DMSO/argon solutions in the presence of POBN resulted in the generation of sixline EPR signal characterized by the asymmetric line-intensities (Figure 2A). The best simulation fit of the experimental spectrum represents superposition of two signals with slightly different hyperfine couplings, i.e. $a_{\mathrm{N}}=1.506 \mathrm{mT}, a_{\mathrm{H}}^{\beta}=0.238 \mathrm{mT} ; g=2.0061$; relative concentration $79 \%$ and $a_{\mathrm{N}}=1.464 \mathrm{mT}, a_{\mathrm{H}}^{\beta}=0.238 \mathrm{mT}$; $g=2.0061 ; 21 \%$, which correspond to the POBN-adducts with carbon-centred radicals. ${ }^{44,} 45$ The detailed composite simulation and 
its decomposition to the individual contributions (Voigtian signals of -POBN-CR1 and POBN-CR2) is shown in Figure S4. Regarding the amine-rich structure of $A C P$, the trapped carbon-centred radicals are therefore most probably formed on the long alkylamino side chains $\mathrm{C}_{8} \mathrm{H}_{17}$ in alpha position of the nitrogen atom. ${ }^{46}$ (Figure 2B). DFT calculations reveal that this radical species is largely more stable than other possible radicals (Figure S5). The DFT spin density plot of the radical $\mathbf{A C P}$ is displayed in Figure $2 \mathrm{C}$. As expected, one notices that the radical is mostly localized on the alpha $\mathrm{C}$ atom. However, a nonnegligible delocalization takes place on the vicinal conjugated sixmember cycle. The suggested and the most stable radical ACP is formed after electron transfer reaction between the photoexcited state of ACP and the amino groups of ACP followed by a hydrogen transfer process, thus leading to aminoalkyl radicals ${ }^{22}$.

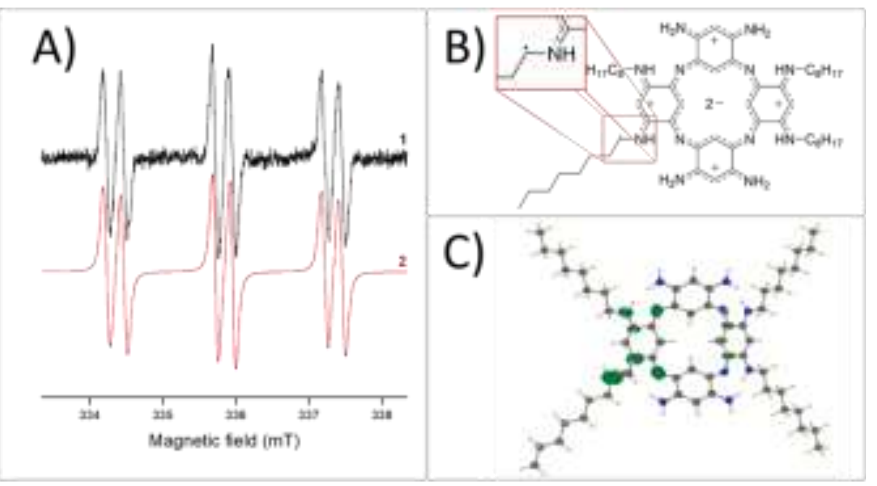

Figure 2. A) Normalized experimental (1) and simulated (2) EPR spectra obtained after $1800 \mathrm{~s}$ in situ LED@VIS nm (450 nm) exposure of deoxygenated DMSO solution of ACP in the presence of POBN spin trap. EPR spectrometer settings: microwave frequency, $\sim 9.43 \mathrm{GHz}$; microwave power, $10.77 \mathrm{~mW}$; center field, $\sim 335.9 \mathrm{mT}$; sweep width, $5 \mathrm{mT}$; gain, $1.00 \times 10^{5}$; modulation amplitude, $0.05 \mathrm{mT}$; sweep time, $45 \mathrm{~s}$; time constant, $10.24 \mathrm{~ms}$; number of scans, $10 . \quad$ B) Representation of the probable carbon-centred radical and C) representation of the radical species with a plot of the DFTcomputed spin density (contour: $8 \times 10^{-3} \mathrm{au}$ ).

Photopolymerization under visible/NIR light. The bio-based soybean oil acrylate (SOA) was chosen as a reference monomer due to its hydrophobic nature: long carbon chains of soybean oil were particularly adapted to the solubilization of ACP, having long alkyl $\mathrm{C}_{8} \mathrm{H}_{17}$ side chains. Kinetic profiles of the SOA photopolymerizations and the final corresponding acrylate conversions under LED@455, $470,505,590,625$ and $660 \mathrm{~nm}$ irradiation at $10 \mathrm{~mW} . \mathrm{cm}^{-2}$ are respectively reported in Figure $\mathbf{3}$ and Table S3. Irradiation at the three longest wavelengths should promote excitation to the third and fourth excited states, whereas the shorter wavelength should yield excitation of even higher-lying states (Table S2) As seen in Figure S2, all these excitations involve significant change of density on the nitrogen atom bearing the alkyl chains. Interestingly, at a fixed intensity of $10 \mathrm{~mW} . \mathrm{cm}^{-2}$ (Figure 3), the conversions are relatively correlated with photon flux absorbed by ACP at each wavelength (Table S3). When a high absorbed photon flux of $25 \times 10^{19}$ photon/ $/ \mathrm{sm}^{2}$ is absorbed at 625 and $660 \mathrm{~nm}$, conversions reach $47 \%$ and $51 \%$ respectively. On the contrary, lower absorbed photon flux at lower wavelengths (almost $18 \times 10^{19}$ photon $/ \mathrm{sm}^{2}$ ) lead to final acrylate conversions between $20 \%$ and $30 \%$. Increasing LEDs intensity to their maximum $\left(55,35,20,50\right.$, and $45 \mathrm{~mW} . \mathrm{cm}^{-2}$ for LED@455, 470, 505, 590, and 625 nm respectively) lead to increase in both conversions and initial polymerization rates (Figure $\mathbf{S 6}$ and Table S3). Although the FRP of SOA at higher wavelengths than 500 $\mathrm{nm}$ has never been reported yet, high final acrylate conversions between $37-56 \%$ were obtained with ACP at the six selected wavelengths. This demonstrates the great reactivity of the carboncentred radical identified by EPR spin trapping, allowing to initiate FRP of SOA. In contrast to most previously reported photoinitiating systems upon far-red irradiation ${ }^{9,37}$, ACP does not require the addition of co-initiators to initiate polymerization. The conversions obtained with ACP/SOA system are far higher than those previously reported photoinitiating system with dimethylaminophenyl phthalocyanine/TMPTA (between 7 and 22\% TMPTA conversions ${ }^{22}$ ), that present an initiation mechanism analogous to the one of the ACP. As a comparison, SOA conversions at $455 \mathrm{~nm}$ and $470 \mathrm{~nm}$ are comparable or higher than the ones obtained previously by our team with two-components systems: anthraquinone, purpurin, mono and tri-allyl purpurin, ${ }^{47}$ associated with iodonium salt. Furthermore, these systems did not initiate polymerization above $530 \mathrm{~nm}$, again contrasting to ACP. Although final SOA conversions remain lower than those reached with classical UV PIs, ${ }^{48}$ ACP is a quite unique example of one-component initiating system acting upon visible and NIR-light. We have also performed DFT calculations to explore the initial reaction step between the radical ACP displayed on Figure 2B and a model of methyl acrylate monomer. That reaction was found to be slightly exergonic ( $\Delta \mathrm{G}$ of $-2.4 \mathrm{kcal}^{\mathrm{mol}}{ }^{-1}$, Figure S7) with a reasonably accessible transition state $\left(21.9 \mathrm{kcal}^{\mathrm{mol}}{ }^{-1}\right)$ above the reactants. The product showed a spin density clearly localized on the acrylate site (Figure S8), confirming that the polymerization reaction can go on from that point.

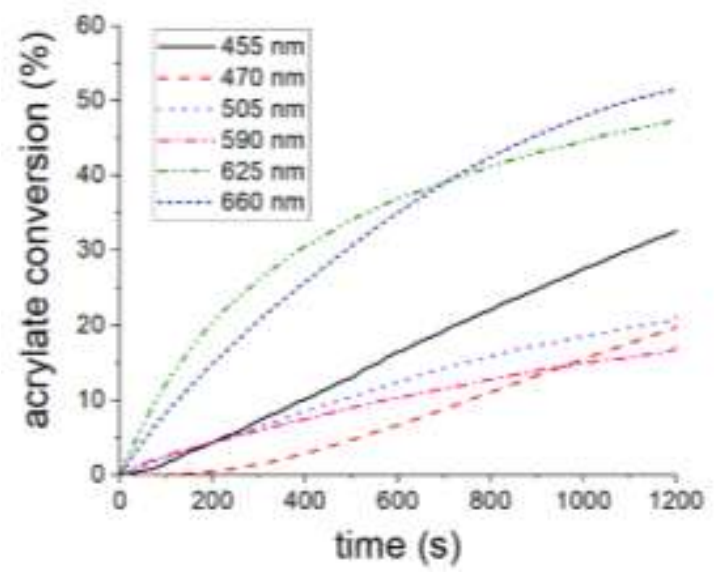

Figure 3. Kinetic profiles for the acrylate polymerization of SOA with ACP (0.5 wt\%) photoinitiating system upon LEDs@455, 470, 505, 590,625 and $660 \mathrm{~nm}$ irradiation. Light intensity $=10 \mathrm{~mW} \cdot \mathrm{cm}^{-2}$.

Fabrication of microstructure under NIR exposure. To demonstrate the applied potential of ACP for NIR microfabrication technologies, a 2D microstructure was synthesized by exciting at $800 \mathrm{~nm}$ a SOAbased formulation containing ACP as NIR photoinitiator. Figure 4 shows a typical scanning electron micrograph (SEM) of a 2D logo. 


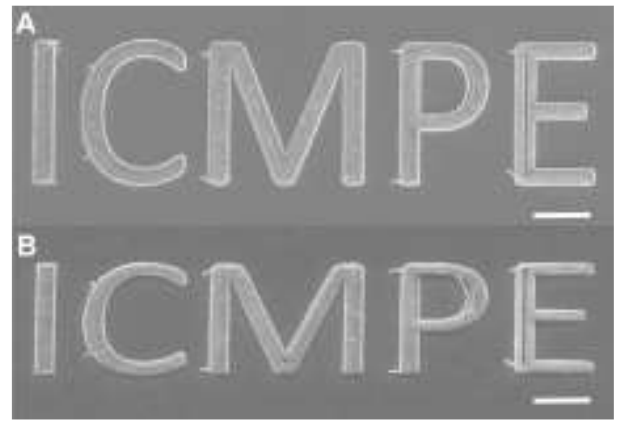

Figure 4. SEMs (A: Face image, B: $40^{\circ}$ tilted image) of a microstructure fabricated by NIR induced polymerization of SOA resin with ACP (0.5 wt\%, $\lambda_{\text {irr: }} 800 \mathrm{~nm}$, scale bar: $25 \mu \mathrm{m}$ ).

Such a pattern was impressed into the resin through stereolithography method which consists in tightly focusing a NIRlaser beam into the photoactive materials. The relative translation of the focus point allows a sequential point-by-point NIR polymerisation process yielding progressively the micropatterned object inside of the formulation. The final structure is next obtained by dissolving away the unexposed resin with ethanol. To the very best of our knowledge, this stands as the first example of 2D printing of SOA derived materials by laser excitation at $800 \mathrm{~nm}$.

\section{Conclusions}

This work highlights new promising opportunities offered by azacalixphyrins. The specific structure of ACP leads to the formation of carbon-centred radicals upon light irradiation, probably via an intramolecular $\mathrm{H}$-abstraction reaction. Thanks to its astonishing absorption properties, ACP demonstrates its capability to initiate FRP in the visible-light, far-red, and NIR ranges. ACP could be used as NIR photoinitiator for the design of well-defined micro-structures by stereolithography. Remarkably, the tremendous advantage of ACP photoinitiating system, compared to other previously reported systems, is its ability to promote polymerization on its own, avoiding thus the introduction of co-initiators.

\section{Conflicts of interest}

"There are no conflicts to declare".

\section{Acknowledgements}

D.J. is indebted to the CCIPL mesocenter installed in Nantes (France), for generous allocation of computational resources. O.S. thanks the Centre National de la Recherche Scientifique, the Ministère de l'Enseignement Supérieur, de la Recherche et de I'Innovation. The EPR study was financially supported by Scientific Grant Agency of the Ministry of Education, Science, Research and Sport of the Slovak Republic (VEGA Project 1/0064/21).

\section{References}

1. Prabhakaran, P.; Lee, K.-S., Photo-polymerization. In Functional Polymers, Jafar Mazumder, M. A.; Sheardown, H.; Al-Ahmed, A., Eds. Springer International Publishing: Cham, 2019; pp 1-52.

2. Yagci, Y.; Jockusch, S.; Turro, N. J. Macromolecules 2010, 43, 6245.

3. Yu, C.; Schimelman, J.; Wang, P.; Miller, K. L.; Ma, X.; You, S.; Guan, J.; Sun, B.; Zhu, W.; Chen, S. Chem. Rev. 2020, 120, 10695.
4. Felipe-Mendes, C.; Ruiz-Rubio, L.; Vilas-Vilela, J. L. Emergent Mater. 2020, 3, 453.

5. Zhang, J.; Xiao, P. Polym. Chem. 2018, 9, 1530.

6. Bagheri, A.; Jin, J. ACS Appl. Polym. Mater. 2019, 1, 593.

7. Bongiovanni, R.; Vacche, S. D.; Vitale, A. Polymers (Basel) 2021, 13, 2293.

8. Garra, P.; Dietlin, C.; Morlet-Savary, F.; Dumur, F.; Gigmes, D.; Fouassier, J.-P.; Lalevée, J. Polym. Chem. 2017, 8, 7088.

9. Bonardi, A. H.; Dumur, F.; Grant, T. M.; Noirbent, G.; Gigmes, D.; Lessard, B. H.; Fouassier, J. P.; Lalevée, J. Macromolecules 2018, 51, 1314. 10. Liu, R.; Zou, X.; Xu, Y.; Liu, X.; Li, Z. Chem. Lett. 2016, 45, 1054.

11. Wu, Z.; Jung, K.; Boyer, C. Angew. Chem. Int. Ed. Engl. 2020, 59, 2013. 12. Breloy, L.; Ait Ouarabi, C.; Brosseau, A.; Dubot, P.; Brezova, V.; Abbad Andaloussi, S.; Malval, J.-P.; Versace, D.-L. ACS Sustain. Chem. Eng. 2019, 7, 19591.

13. Condat, M.; Mazeran, P.-E.; Malval, J.-P.; Lalevée, J.; Morlet-Savary, F.; Renard, E.; Langlois, V.; Abbad Andalloussi, S.; Versace, D.-L. RSC Adv. 2015, 5, 85214

14. Sautrot-Ba, P.; Jockusch, S.; Malval, J.-P.; Brezová, V.; Rivard, M.; Abbad-Andaloussi, S.; Blacha-Grzechnik, A.; Versace, D.-L. Macromolecules 2020, 53, 1129.

15. Breloy, L.; Losantos, R.; Sampedro, D.; Marazzi, M.; Malval, J.-P.; Heo, Y.; Akimoto, J.; Ito, Y.; Brezová, V.; Versace, D.-L. Polym. Chem. 2020, 11, 4297.

16. Xiao, P.; Zhang, J.; Dumur, F.; Tehfe, M. A.; Morlet-Savary, F.; Graff, B.; Gigmes, D.; Fouassier, J.-P.; Lalevée, J. Progr. Polym. Sci. 2015, 41, 32. 17. Mokbel, H.; Graff, B.; Dumur, F.; Lalevee, J. Macromol. Rapid Comm. 2020, 41, e2000289.

18. Strehmel, B.; Schmitz, C.; Kutahya, C.; Pang, Y.; Drewitz, A.; Mustroph, H. Beilstein J. Org. Chem. 2020, 16, 415.

19. Dika, I.; Malval, J.-P.; Soppera, O.; Bardinal, V.; Barat, D.; Turck, C.; Spangenberg, A.; Bruyant, A. Chem. Phys. Lett. 2011, 515, 91.

20. Dika, I.; Diot, F.; Bardinal, V.; Malval, J.-P.; Ecoffet, C.; Bruyant, A.; Barat, D.; Reig, B.; Doucet, J.-B.; Camps, T.; Soppera, O. J. Polym. Sci. 2020, 58, 1796 .

21. Marcille, H.; Malval, J.-P.; Presset, M.; Bogliotti, N.; BlachaGrzechnik, A.; Brezová, V.; Yagci, Y.; Versace, D.-L. Polym. Chem. 2020, 11, 4237.

22. Breloy, L.; Alcay, Y.; Yilmaz, I.; Breza, M.; Bourgon, J.; Brezová, M.; Yagci, Y.; Versace, D.-L. Polym. Chem. 2021, 12, 1273.

23. Huang, Y.; Li, X.; Le Li, J.; Zhang, B.; Cai, T. Macromolecules 2018, 51 7974.

24. Shanmugam, S.; Xu, J.; Boyer, C. J. Am. Chem. Soc. 2015, 137, 9174. 25. Shanmugam, S.; Xu, J.; Boyer, C. Chem. Sci. 2015, 6, 1341.

26. Shanmugam, S.; Xu, J.; Boyer, C. Polym. Chem. 2016, 7, 6437.

27. Shanmugam, S.; Xu, J.; Boyer, C. Macromolecules 2016, 49, 9345.

28. Wu, C.; Shanmugam, S.; Xu, J.; Zhu, J.; Boyer, C. Chem. Comm. 2017, 53, 12560.

29. Xu, J.; Shanmugam, S.; Boyer, C. ACS Macro Lett. 2015, 4, 926.

30. Xu, J.; Shanmugam, S.; Fu, C.; Aguey-Zinsou, K. F.; Boyer, C. J. Am. Chem. Soc. 2016, 138, 3094.

31. Zhou, Y.; Zhang, Z.; Reese, C. M.; Patton, D. L.; Xu, J.; Boyer, C.; Postma, A.; Moad, G. Macromol. Rapid Comm. 2019, 41, 1900478.

32. Corrigan, N.; Xu, J.; Boyer, C. Macromolecules 2016, 49, 3274.

33. Breloy, L.; Brezová, V.; Blacha-Grzechnik, A.; Presset, M.; Yildirim, M. S.; Yilmaz, I.; Yagci, Y.; Versace, D.-L. Macromolecules 2019, 53, 112.

34. Al Mousawi, A.; Poriel, C.; Dumur, F.; Toufaily, J.; Hamieh, T.; Fouassier, J.-P.; Lalevée, J. Macromolecules 2017, 50, 746.

35. Korkut, S. E.; Temel, G.; Balta, D. K.; Arsu, N.; Şener, M. K. J. Lumines. 2013, 136, 389.

36. Bonardi, A.-H.; Bonardi, F.; Noirbent, G.; Dumur, F.; Dietlin, C.; Gigmes, D.; Fouassier, J.-P.; Lalevée, J. Polym. Chem. 2019, 10, 6505.

37. Noirbent, G.; Xu, Y.; Bonardi, A.-H.; Gigmes, D.; Lalevée, J.; Dumur, F. Eur. Polym. J. 2020, 139, 110019. 
38. Rodgers, Z. L.; Hughes, R. M.; Doherty, L. M.; Shell, J. R.; Molesky, B. P.; Brugh, A. M.; Forbes, M. D. E.; Moran, A. M.; Lawrence, D. S. J. Am. Chem. Soc. 2015, 137, 3372.

39. Chen, Z.; Giorgi, M.; Jacquemin, D.; Elhabiri, M.; Siri, O. Angew. Chem. Int. Ed. Engl. 2013, 52, 6250.

40. Chen, Z.; Haddoub, R.; Mahe, J.; Marchand, G.; Jacquemin, D.; Andeme Edzang, J.; Canard, G.; Ferry, D.; Grauby, O.; Ranguis, A.; Siri, O. Chemistry 2016, 22, 17820.

41. Lavaud, L.; Pascal, S.; Metwally, K.; Gasteau, D.; Da Silva, A.; Chen, Z.; Elhabiri, M.; Canard, G.; Jacquemin, D.; Siri, O. Chem. Comm. 2018, 54, 12365.

42. Lavaud, L.; Azarias, C.; Canard, G.; Pascal, S.; Jacquemin, D.; Siri, O. New J. Chem. 2020, 44, 18130.

43. Lavaud, L.; Azarias, C.; Canard, G.; Pascal, S.; Galiana, J.; Giorgi, M.; Chen, Z.; Jacquemin, D.; Siri, O. Chem. Comm. 2020, 56, 896.

44. Kleinjans, J. C. S.; Van Herwijnen, M. H. M.; Van Maaneny, J. M. S.; Maas, L. M.; De Kok, T. M. C. M.; J., M. H. J.; Briedé, J. J. Carcinogenesis 2004, 25, 1249.

45. Xu, Y.; Gu, Y.; Qian, S. Y. Int. J. Mol. Sci. 2012, 13, 14648.

46. Arnoux, C.; Konishi, T.; Van Elslande, E.; Poutougnigni, E.-A.; Mulatier, J.-C.; Khrouz, L.; Bucher, C.; Dumont, E.; Kamada, K.; Andraud, C.; Baldeck, P.; Banyasz, A.; Monnereau, C. Macromolecules 2020, 53, 9264.

47. Sautrot-Ba, P.; Brezová, V.; Malval, J.-P.; Chiappone, A.; Breloy, L.; Abbad-Andaloussi, S.; Versace, D.-L. Polym. Chem. 2021, 12, 2627.

48. Breloy, L.; Negrell, C.; Mora, A.-S.; Li, W.-S. J.; Brezová, V.; Caillol, S.; Versace, D.-L. Eur. Polym. J. 2020, 132, 109727. 